\title{
Preeclampsia as a Risk Factor for Damage of the Cochlear Outer Hair Cells Function
}

\author{
Oppy Surya Atmaja, Kartono Sudarman, and Agus Surono \\ Department of Otorhinolaryngology Head and Neck Surgery, Faculty of Medicine, Universitas Gadjah Mada, Sekip Utara, \\ Yogyakarta 55281, Indonesia \\ Correspondence should be addressed to Agus Surono; agus_srn@yahoo.com
}

Received 20 December 2015; Revised 22 February 2016; Accepted 21 April 2016

Academic Editor: Jareen K. Meinzen-Derr

Copyright (C) 2016 Oppy Surya Atmaja et al. This is an open access article distributed under the Creative Commons Attribution License, which permits unrestricted use, distribution, and reproduction in any medium, provided the original work is properly cited.

Preeclampsia is one of the most common complications of pregnancy in the world. In Indonesia, the incidence of preeclampsia lies within 3-10\% of all pregnancies every year. Preeclampsia is a multisystem disorder that causes endothelial dysfunction and vasospasm that may lead to ischemia and organ damage especially to the end organs. Cochlea serves as an end organ and is therefore vulnerable to damage under ischemic conditions. This research aimed to understand the role of preeclampsia on the destruction of cochlear outer hair cells function. Subjects were pregnant women who were hospitalized in the Obstetrics and Gynecology Ward of Sardjito Hospital. Diagnosis of preeclampsia was obtained by defining level of high blood pressure measurement and quantitative 24 hours of proteinuria. Meanwhile, cochlear outer hair cell function was measured by the distortion product otoacoustic emission (DPOAE). The DPOAE results showed that REFER presented in $6(10 \%)$ patients with preeclampsia and none in those without preeclampsia groups. This result demonstrated preeclampsia as one of the risk factors for impaired function of cochlear outer hair cells.

\section{Introduction}

Preeclampsia is a pregnancy specific syndrome with reduced organ perfusion resulting in the occurrence of vasospasm and endothelial activation. It is a complication of pregnancy characterized by hypertension that usually begins after 20 weeks of pregnancy which is accompanied by proteinuria [1]. The number of preeclampsia cases is estimated to be about $5-7 \%$ of all pregnancies. In the USA, the number of preeclampsia cases was approximately $5 \%$ of all pregnancies. The number of preeclampsia cases in Indonesia differs according to the region but ranges within 3-10\%. Based on the medical records at Sardjito Hospital in Yogyakarta, there were 277 preeclampsia cases from 2009 to 2011. The etiology and pathophysiology of preeclampsia are still not fully understood; there are still plenty of controversies; this condition is often referred to as the "the disease of theories" $[1,2]$. In cases of preeclampsia and eclampsia where the destruction of the pathological function of organs and systems was found, the cause may be vasospasms and ischemia $[1,2]$. Previous research demonstrated the complications of preeclampsia on a number of organs including the heart, brain, liver, eyes, and kidneys [3]. These complications might be caused by ischemia, vasoconstriction, and immunological reactions. Although the inner ear is also similarly susceptible, there is very little information on how preeclampsia can cause the destruction of cochlear outer hair cells function $[3,4]$. The inner ear affected by vascularization of the end artery is especially susceptible to the effects of vasospasms and ischemia [4]. Blood vessel damage to the cochlea interferes with cochlear vascularization resulting in a disruption of nutrients supply and oxygen needed by the cells in order to maintain the cochlear function [5].

Evoked otoacoustic emissions (OAEs) are generated by the outer hair cells in response to sound presented to the ear, and they can provide objective information about the integrity of the outer hair cells $[6,7]$. Two types of evoked OAEs are clinically used: transient evoked otoacoustic emissions (TEOAEs) and distortion product otoacoustic emissions (DPOAEs). TEOAE is evoked using click-sound (broad frequency range) or tone burst (brief duration pure tone) stimuli with the onset being very fast (milliseconds) and has intensity of $50 \mathrm{~dB}$. The evoked response from click-sound 
covers the frequency range up to around $4000 \mathrm{~Hz}$, while a tone burst will elicit a response from the region that has same frequency as the pure tone. The spectrum of TEOAE is $500-4500 \mathrm{~Hz}$ for adult and $5000-6000 \mathrm{~Hz}$ for baby. TEOAE is preferable for screening purpose such as baby hearing screening. DPOAE is evoked using a pair of primary tones $f_{1}$ and $f_{2}$ simultaneously with particular intensity (usually either $65-55 \mathrm{~dB}$ SPL or 65 for both) and ratio $\left(f_{1}: f_{2}\right)$. The evoked responses from these stimuli occur at frequencies $\left(f_{\mathrm{dp}}\right)$ mathematically related to the primary frequencies, with the two most prominent being $f_{\mathrm{dp}}=2 f_{1}-f_{2}$ (the "cubic" distortion tone, most commonly used for hearing screening) and $f_{\mathrm{dp}}=f_{2}-f_{1}$ (the "quadratic" distortion tone, or simple difference tone). The spectrum of DPOAE is wider than TEOAE and able to achieve up to $10,000 \mathrm{~Hz}$. DPAOE is more sensitive in measuring the cochlear outer hair cell function and more noise-resistent compared to TEOAE. DPOAE is more valuable for monitoring cochlear changes clinically $[8,9]$. DPOAE has been widely used to diagnose the peripheral auditory neuropathy and evaluate ototoxic administration, noise induced, and other cochlear disorders. This study aimed to understand the role of preeclampsia on the destruction of cochlear outer hair cells function.

\section{Materials and Methods}

This study was approved by the Institutional Review Board for the Protection of Human Subjects at the author's home institution. The research design was a cross-sectional one. One hundred and twenty patients were enrolled at the Obstetrics and Gynecology Ward of Sardjito Hospital, Yogyakarta, Indonesia, from February to September of 2012. Samples were selected consecutively. Inclusion criteria for this study were female patients after 20th week of pregnancy who were hospitalized in the Obstetrics and Gynecology Ward, aged under 40 years, and they agreed to participate in this study by signing the informed consent. Exclusion criteria included patients with history of previous preeclampsia, chronic hypertension, diabetes mellitus, a twin pregnancy, history of ototoxic drug consumption, acute inflammation of nose and throat, and external ear abnormalities. The samples were divided into two groups, with and without preeclampsia. The preeclampsia group was defined by hypertensive blood pressure (diastolic blood pressure was more than $90 \mathrm{mmHg}$ ) and quantitative 24 hours of proteinuria.

The DPOAE equipment was fully calibrated by a qualified technician within the previous year. All testing was completed by the same investigator. Otoscopy was performed and any cerumen was removed, if necessary, before testing initiated. Patients were seated in a comfortable chair. The right ear was always tested first for consistency. The DPOAE AccuScreen PRO (Fischer-Zoth Diagnosesysteme Gmbh, Walter-Kolbenhoff-Strasse 34, 82110 Germering, Germany) was used for DPOAE recording. Following appropriate configuration of stimuli waveform, DPAOEs were measured in diagnostic mode by giving non-linier clicks. An $f_{2} / f_{1}$ ratio was kept at 1.2 and $f_{1}$ and $f_{2}$ levels of $65 \mathrm{~dB}$ SPL and $55 \mathrm{~dB}$ SPL, respectively. The sampling rate was $16,000 \mathrm{~Hz}$. A minimum of 30 frames and a maximum of $1,200 \mathrm{~Hz}$ frames
TABLE 1: Characteristic sample.

\begin{tabular}{lccccc}
\hline & \multicolumn{3}{c}{ Preeclampsia } & \multicolumn{2}{c}{ Without } \\
preeclampsia & $p$ \\
& $n$ & $(\%)$ & $n$ & $(\%)$ & \\
\hline $\begin{array}{l}\text { Age distribution } \\
\text { (years) }\end{array}$ & & & & & \\
$\quad<20$ & 9 & 15.0 & 2 & 3.3 & \\
$20-35$ & 38 & 63.3 & 50 & 83.3 & 0.495 \\
$>35(36-39)$ & 13 & 21.7 & 8 & 13.3 & \\
Parity & & & & & \\
$\quad$ Primigravida & 25 & 41.7 & 25 & 41.7 & 1.00 \\
$\quad$ Multigravida & 35 & 58.3 & 35 & 58.3 & \\
\hline
\end{tabular}

$p<0.05$.

were collected per ear, and the noise rejection level was $20 \mathrm{~dB}$ SPL. DPAOEs were considered present when the amplitude of the emission was at least $6 \mathrm{~dB}$ above the noise floor of the corresponding frequency. DPOAEs corresponding to the frequency of $2 f_{1}-f_{2}$ were measured at three points per octave, and results were analyzed at the following $f_{2}$ frequencies: $1,187 \mathrm{~Hz}, 1,500 \mathrm{~Hz}, 1,906 \mathrm{~Hz}, 2,531 \mathrm{~Hz}, 3,031 \mathrm{~Hz}$, $3,812 \mathrm{~Hz}, 4,812 \mathrm{~Hz}$, and $6,031 \mathrm{~Hz}$. A probe check-fit procedure was completed prior to each measurement to ensure that the primary levels were within a tolerance of $\pm 5 \mathrm{~dB}$. Each variable association was analyzed using chi-square and independent sample $t$-test with a significance level of $p \leq 0.05$.

\section{Results}

In the aforementioned period, this study recruited 120 patients consisting of 60 pregnant women with preeclampsia and 60 women with normal pregnancies. The result showed that the most patients with and without preeclampsia ranged within $20-35$ years; they were $63.3 \%$ and $83.3 \%$, respectively $(p=0.495)$ (Table 1). There was no significant difference between maternal ages in both groups. The mean age of the preeclampsia group was $29.73 \pm 6.78$ and that of without preeclampsia group was $28.96 \pm 5.4$. The most subjects with and without preeclampsia were multigravida, accounting to $58.3 \%$. There was no significant difference between parity and preeclampsia. The mean gestational age in weeks in the preeclampsia group was $35.6 \pm 4.15$, while that of without preeclampsia group was $39.18 \pm 0.92$ [10]. In order to measure cochlear outer hair cells function, all participants were assessed by DPOAEs (Table 2). There are two types of DPOAE result: PASS and REFER. The PASS is defined as a normal outer hair cells function, and the REFER is defined as an absent DPOAE for at least two frequencies in each ear (as an outer hair cells dysfunction). The result of DPOAEs showed that the REFER was identified in $6(10 \%)$ patients of the preeclampsia group. In the group without preeclampsia, all the DPOAEs result was PASS ( $p=0.027$ ). Among the preeclampsia group with REFER result, $4(66.7 \%)$ patients were at the age of $20-35$, and the others were $<20$ and $>35$ years old. All patients with DPOAE REFER were in a severe degree of preeclampsia (Table 2) [10]. This result supported 
TABLE 2: Results of DPOAEs screening.

\begin{tabular}{lccccc}
\hline & \multicolumn{5}{c}{ DPOAE } \\
& \multicolumn{2}{c}{ REFER } & \multicolumn{2}{c}{ PASS } & $p$ \\
& $n$ & $\%$ & $n$ & $\%$ & \\
\hline Group & & & & & \\
$\quad$ Preeclampsia & 6 & 10 & 54 & 90 & 0.027 \\
$\quad$ Without preeclampsia & 0 & 0 & 60 & 100 & \\
$\quad$ Degree of preeclampsia & & & & & \\
$\quad$ Severe & 6 & 10 & 52 & 96.3 & 1.000 \\
$\quad$ Mild & 0 & 0 & 2 & 3.7 & \\
\hline$p<0.05$. & & & & &
\end{tabular}

TABLE 3: Distribution of blood pressure levels according to DPOAE screening test results.

\begin{tabular}{lccccc}
\hline & DPOAE & $n$ & Average \pm SD & $p$ & Mean CI (95\%) \\
\hline \multirow{2}{*}{ Systolic } & REFER & 6 & $158.33 \pm 13.29$ & 0.012 & $5.1-41.9$ \\
& PASS & 114 & $134.78 \pm 22.4$ & & \\
\multirow{2}{*}{ Diastolic } & REFER & 6 & $101.67 \pm 4.08$ & 0.006 & $4.46-25.44$ \\
& PASS & 114 & $86.71 \pm 12.90$ & & \\
\hline
\end{tabular}

$p<0.05, t$-test.

the hypothesis that preeclampsia was a risk factor for damage to cochlear outer hair cells function.

We then analyzed the distribution of blood pressure levels according to the DPOAE screening test results (Table 3 ). The result demonstrated that the mean of systolic blood pressure for group with a DPOAE result of REFER was $158.33 \pm 13.29$, while the mean of systolic blood pressure in the group with PASS was $134.78 \pm 22.44$ with $p=0.012$ (95\% CI 5.1 to 41.9). The mean of systolic rates in the group with a result of REFER was higher than the PASS result and statistically significant. The mean of diastolic blood pressure for the group with DPOAE result of REFER was $101.67 \pm 4.082$, while the average diastolic blood pressure in the group with PASS was $86.71 \pm 12.869$ with $p=0.006$ (95\% CI 4.46 to 25.44$)$ [10]. The mean diastole of REFER was higher compared to the PASS group and statistically significant.

\section{Discussion}

This study identified 6 (10\%) samples of the patients who had an impaired function of the outer hair cells of the cochlea. They were 2 patients who had disorders of the left ear, 3 patients who had disorders of the right ear, and one patient who had disorders in both ears. Prevalence ratio (PR) resulted in a PR value of 7 (95\% CI 0.89 to 55.23$)$. This demonstrated that pregnant women suffering from preeclampsia had potential damage to the outer hair cells of the cochlea which was 7 times greater than pregnant women without preeclampsia. In the group without preeclampsia, all samples were DPOAE PASS. This is the first research in Indonesia to study the prevalence of cochlear outer hair cells dysfunction in preeclampsia patients, specifically in Yogyakarta region. Vasospasm which occurred in preeclampsia and eclampsia would lead to tissue ischemia and end artery organ abnormalities $[2,11]$. Our result supported the data that had been reported by Lin et al. [8]. They conducted animal studies to assess the effects of transient cochlear ischemia, concluding that cochlear ischemia which occurred within 15 minutes could lead to the cochlear outer hair cells malfunctioning which was more severe in the basal region compared to the apical region of the cochlea. It was possible that the basal region of the cochlea has higher rate of oxygen consumption than the apical region and vice versa. Reserve of glycogen as the energy of the organ corti at the apical region was more available than in the basal region. The conclusion of the study conducted by Lin et al. [8] was different from the hypothesis proposed by Baylan et al. [3] where cochlear hair cell function disturbances caused by vasospasm and ischemia were specified to the apical region because the apex was more sensitive to vascular changes. High blood pressure itself can result in dysfunction of the cochlea as described in study by de Moraes Marchiori et al. [11], who conducted a study of 154 cases of hypertension, in individuals aged 45-64 years, and found that a total of $46.8 \%$ had sensorineural hearing loss with $\mathrm{OR}=2.06$ ( $95 \%$ CI 1.26 to 3.39 ).

Results in this study were in accordance with research conducted by Bakhshaee et al. [4] who discovered as much as $13.5 \%$ of the preeclampsia group to have REFER results in the DPOAE with an OR of 1.87 (95\% CI 1.26 to 2.77) and the entire control group of pregnant women without preeclampsia to have PASS results in the DPOAE, suggesting that preeclampsia had an influence on hearing ability. Results of the study found that none of the patients in the group without preeclampsia had impaired function of outer hair cells of the cochlea [3], in contrast to a study conducted by Wang and Young [12] who found that sensory neural hearing loss occurred in as much as 3\% of normal pregnancies; this was the case allegedly due to maternal physiological changes such as hormones, electrolytes, metabolism, and the effects of psychological changes that occur during pregnancy. This study showed that, of those in the preeclampsia group who had a result of REFER from DPOAE screening, only one patient had a bilateral abnormality and the rest were unilateral.

\section{Conclusion}

Preeclampsia plays a role as a risk factor of cochlear outer hair cells destruction that can lead to permanent hearing loss. Although preeclampsia mostly resolves after delivery, cochlear damage and permanent hearing loss may remain unchanged in patients with preeclampsia. Some shortcomings of this study were not being capable of testing the function of the middle ear objectively or performing any hearing threshold test using audiometry. Further research is needed to examine middle ear function objectively with tympanometry and also the use of audiometry to assess the hearing thresholds as well as the need to evaluate whether the results of the DPOAE will remain the same or return to normal after giving birth. Based on this research, it is expected that obstetricians should work together with otolaryngologists in order to detect the complications of 
preeclampsia on the inner ear so that any damage will be immediately resolved.

\section{Additional Points}

The DPOAEs can be used as a screening tool for cochlear outer cell damage in preeclampsia patients.

\section{Competing Interests}

The authors state no conflict of interests.

\section{References}

[1] F. G. Cunningham, N. F. Gant, K. J. Leveno, S. L. Bloom, J. C. Hauth, and D. J. Rouse, Williams Obstetrics, McGraw-Hil, New York, NY, USA, 23th edition, 2010.

[2] J. C. Hauth, M. G. Ewell, R. J. Levine et al., "Pregnancy outcomes in healthy nulliparas who developed hypertension. Calcium for preeclampsia prevention study group," Obstetrics and Gynecology, vol. 95, no. 1, pp. 24-28, 2000.

[3] M. Y. Baylan, U. Kuyumcuoglu, A. Kale, Y. Celik, and I. Topcu, "Is preeclampsia a new risk factor for cochlear damage and hearing loss?” Otology and Neurotology, vol. 31, no. 8, pp. 1180$1183,2010$.

[4] M. Bakhshaee, M. Hassanzadeh, N. Nourizadeh, E. Karimi, T. Moghiman, and M. Shakeri, "Hearing impairment in pregnancy toxemia," Otolaryngology-Head and Neck Surgery, vol. 139, no. 2, pp. 298-300, 2008.

[5] M. Thierry, J. Chazal, J. Gabrillargus, L. Gilain, and P. Avan, "Cochlear blood supply: an update on anatomy and function," French Oto-Rhino-Laryngologie, vol. 88, pp. 81-88, 2005.

[6] J. A. L. Miller, L. Marshall, and L. M. Heller, "A longitudinal study of changes in evoked otoacoustic emissions and pure-tone thresholds as measured in a hearing conservation program," International Journal of Audiology, vol. 43, no. 6, pp. 307-322, 2004.

[7] B. L. Lonsbury-Martin, M. L. Whitehead, and G. K. Martin, "Clinical applications of otoacoustic emissions," Journal of Speech and Hearing Research, vol. 34, no. 5, pp. 964-981, 1991.

[8] C. D. Lin, I. H. Wei, M. H. Tsai et al., "Change in guinea pig cochlea after transient cochlear ischemia," Neuroreport, vol. 21, no. 15, pp. 968-975, 2010.

[9] B. A. Preive, "Otoacoustic emmisions in infant and children," in Pediactric Audiology, J. R. Madell and C. Flexer, Eds., pp. 123131, Thieme, New York, NY, USA, 2008.

[10] O. S. Atmaja, Preeklampsia sebagai salah satu faktor risiko terhadap kerusakan fungsi sel rambut luar koklea [M.S. thesis], Universitas Gadjah Mada, Yogyakarta, Indonesia, 2013.

[11] L. L. de Moraes Marchiori, E. de Almeida Rego Filho, and T. Matsuo, "Hypertension as a factor associated with hearing loss," Brazilian Journal of Otorhinolaryngology, vol. 72, no. 4, pp. 533540, 2006.

[12] Y.-P. Wang and Y.-H. Young, "Experience in the treatment of sudden deafness during pregnancy," Acta Oto-Laryngologica, vol. 126, no. 3, pp. 271-276, 2006. 


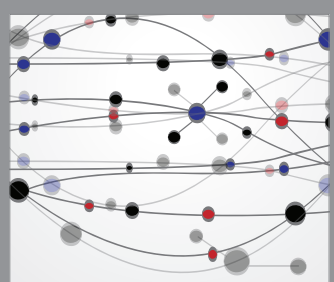

The Scientific World Journal
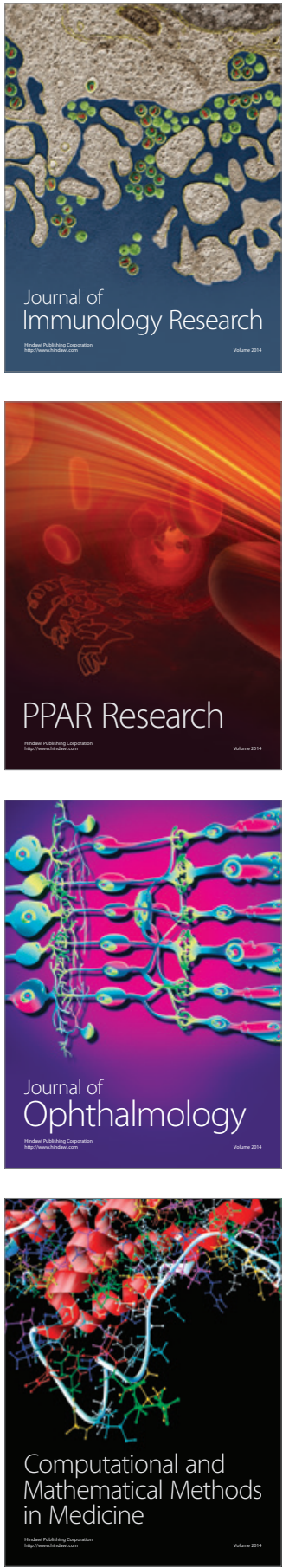

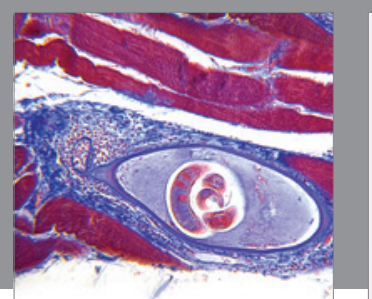

Gastroenterology Research and Practice

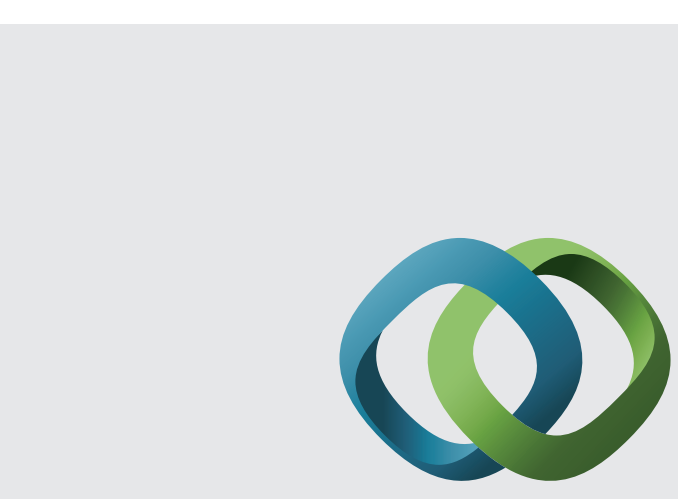

\section{Hindawi}

Submit your manuscripts at

http://www.hindawi.com
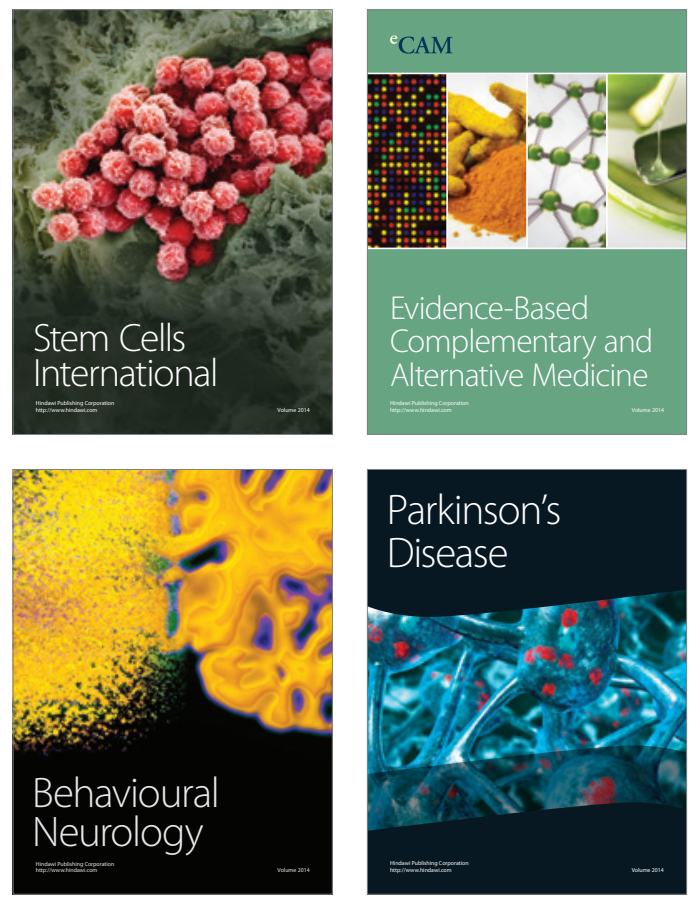
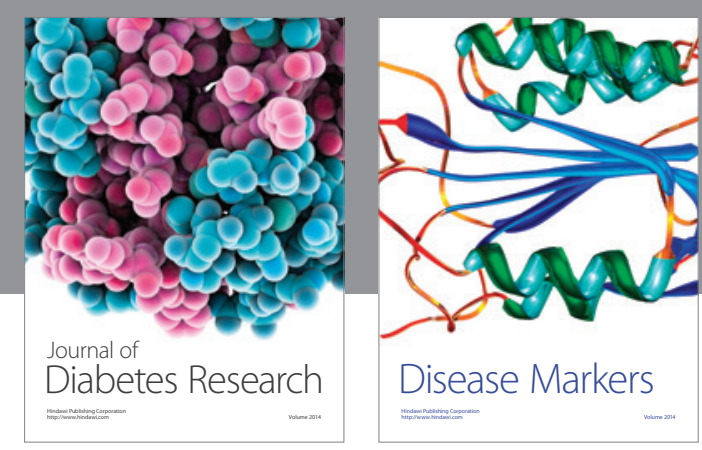

Disease Markers
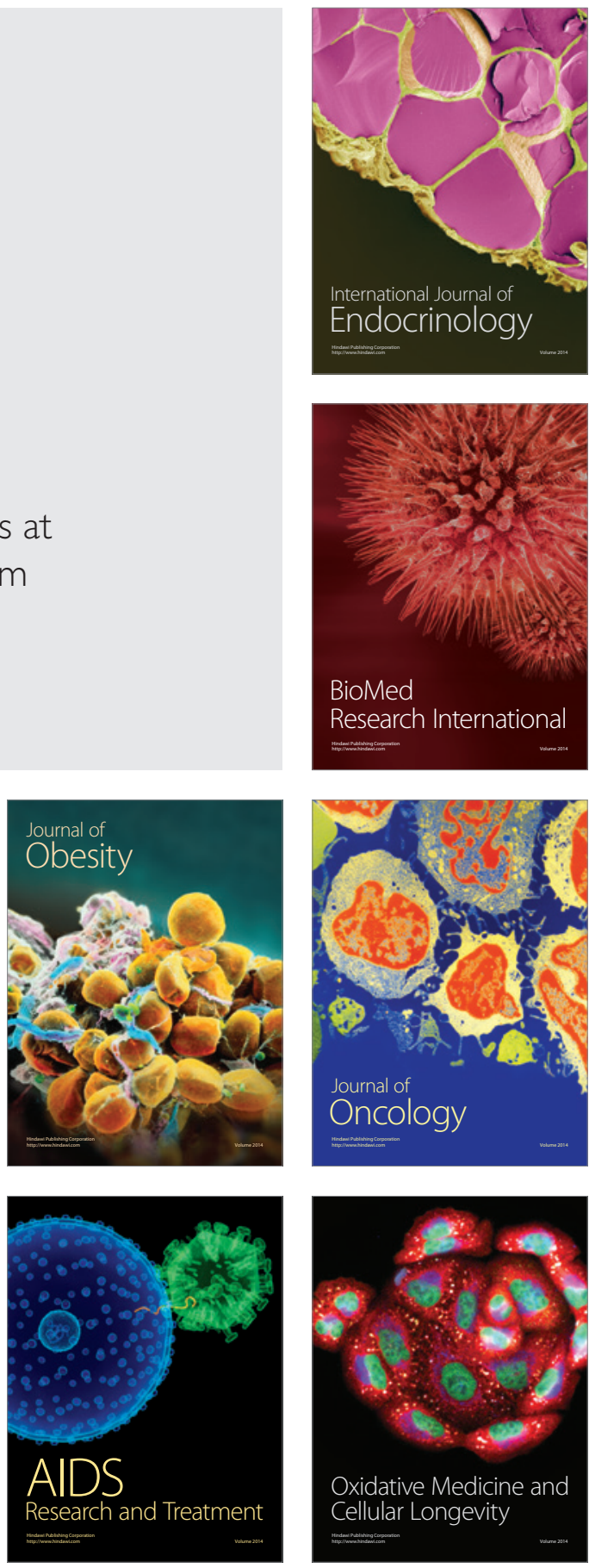